\title{
Bemerkungen zu dem vorstehenden Aufsatz.
}

Von Prof. Fr. Sehultze in Bonn.

Am liebsten würde ich nicht noch einmal das Wort zur Diskussion über das in Rede stehende Thema ergreifen. Da aber die Redaktion dieses Blattes sich einmal die liebenswürdige Mühe gegeben hat, mir den Aufsatz von Herrn Dr. Strubell zur eventuellen Anfügung etwaiger Aeusserungen zuzusenden, so gestatte ich mir kurz das Folgende zu bemerken:

Die von mir gegebene Krankengeschichte wurde im Interesse der etwaigen Leser auf das kürzeste Maass zusammengezogen. Darum wurde auch nicht erwähnt, dass wir selbstverständlich bei der Zunahme der erheblichen Dyspnoë auch an eine Kehlkopfstenose gedacht haben. Es wurde sogar im Einvernehmen mit unserem chirurgischen Collegen, Herrn Dr. Graff, der den Kranken mitbehandelte, alles für eine Tracheotomie vorbereitet, die aber unterblieb, weil niemals ein Stridor eintrat und wir in Folge davon die Athmungsstörung auf andere Ursachen beziehen mussten. Eine laryngoskopische Untersuchung, die auch in unserer Klinik nicht so ganz selten vorgenommen wird, war wegen der starken Schwellung der Schleimhaut der Mundhöhle und Lippen nicht ausführbar. Eine Cyanose bestand nicht.

Ueber die etwaige Grösse der Halsdrüsen liess sich wegen der starken Oedeme der Halshaut nichts aussagen; ich glaube auch nicht, dass es Herrn Collegen Strubell gelungen wäre, in diesem Falle Genaueres darüber herauszubekommen.

Im übrigen überlasse ich das Urtheil über das thatsächliche Material unserer Arbeiten und der in ihnen enthaltenen Schlussfolgerungen dem Urtheile der Fachgenossen. 